\title{
TACKLING GUN VIOLENCE IN INDIA
}

Gun-related violence has far-reaching adverse impacts on all levels of society. In addition to murder and injury, gun violence can exacerbate cycles of highly localised urban poverty, inequality and vulnerability. India has the second largest number of homicides in the world but the issue is little discussed. In contrast to well-known gun violence in the Americas and Africa, and is absent from public security and development agendas. With criminal violence generating at least ten times more deaths and injuries in India than terrorism and conflict, there is an urgent need to re-orient policies towards preventative frameworks and to focus efforts on rapidly growing mid-size cities suffering from under-resourced police forces and rising youth unemployment.

\section{Emerging trends of growing gun-related violence in urban India}

India registers the second largest number of homicides in the world, though the issue is absent from the public security and development agendas: India recorded 43,355 intentional homicides in 2012 or a rate of 4.5 per 100,000. This is more than four times the rate of the UK. Owing to the scale of unregistered births and deaths and the poor quality of police data collection, it is likely that the prevalence is much higher. Even assuming this conservative count, criminal violence generates at least ten times more deaths and injuries in India than terrorism and conflict.

India's challenges with gun-related violence are highly concentrated in a limited number of states: Manipur, Nagaland, Bihar, Jharkhand, Jammu and Uttar Pradesh account for over 60 per cent of all registered homicides involving a firearm in 2008. While murder rates associated with firearms declined from 1999 to 2008 (the latest years for which time series data are available), some cities nevertheless experienced a sharp spike in gun violence. In these states, the predominantly rural phenomenon of 'Dabangs' and 'Bahubalis' (gang leaders) using firearms to secure territory and intimidate political rivals is increasingly apparent in semi-urban and urban areas.

A comparatively small number of intermediate and large cities register a disproportionate amount of gun violence: four of the top five most violent cities in terms of murder by firearms are located in Uttar Pradesh. The most violent cities are not mega-cities, but rather mid-sized cities of between one and three million people. These mid-sized cities continue to grow rapidly and feature disproportionately large populations of unemployed and under-educated youth. They are also exhibiting severely under-resourced services, including public police forces.

\section{A mixed arsenal of weapons with weak regulations}

The decentralization of the arms procurement is devolving purchasing authority from the federal government to security agencies, states and cities: as a result, formal suppliers are diversifying arms types and calibre. Indian security agencies are also increasingly modernising their arsenals through imports as opposed to local production. Indian states and agencies pursue distinct and individual armaments policies ranging from purchasing older domestic equipment to importing the most advanced models available. No standard tagging and tracing guidelines are applied. The result is a mixed arsenal of state-of-the-art and older models.

There is mixed evidence of robust storage and destruction policies for firearms across India: as Indian state agencies continue upgrading their military and policing capacities, the stockpile of out-dated weapons (and ammunition) continues to grow. Vast quantities of older weapons - many of them considered obsolete in other parts of the world - continue circulating in India. Nor does there appear to be a culture of destroying surplus weaponry and ammunition, thus ensuring a steady supply to civilian markets. 
Domestic gun regulation is weak and ineffective: there are approximately 40 million civilian-owned firearms in India (over 6 per cent of civilian-owned firearms globally). Known locally as 'kattas', about 85 per cent of them are unlicensed. These range from simple flintlock-like muskets to sophisticated semi-automatic weapons. This compares to roughly 2.6 million in the hands of the military, 1.3 million held by paramilitaries and 1.7 million held by police. Even though the rate of gun-related murders is low (accounting for just 12 per cent of all murders in 2008), 86 per cent of gun-related deaths were caused by unlicensed firearms

\section{Businesses becoming armed}

There is growing evidence that Indians connected to urban-based service industries that are cash dependent are resorting to arming themselves: many owners of small, medium and large businesses in India in India are targets of extortion and even kidnapping. These include builders, civil contractors, film/television entrepreneurs, hotel/bar/cinema theatre owners, and jewellers. There are signs that elites and others are increasingly using firearms for self-protection and sometimes to counter-intimidate their would-be attackers and rivals.

\section{Growing narcotics activity}

There are also incipient signs of potential links between gun violence and narco-activity: according to the most recent data from the Narcotics Control Bureau (NCB), the quantity of drugs seized in India has increased by more than 450 per cent between 2011 and 2013, while the number of cases related specifically to cocaine seizures increased by more than 70 per cent since 2009. Drug cartels based in Latin America (particularly Colombia) are trying new ways of smuggling pure cocaine into India. This may be due to rising consumption among India's middle and upper-income groups in the wake of growing prosperity. It may also be tied to transhipment to other markets.

\section{Lessons from Latin America and the Caribbean}

Violence is not innate, or somehow naturally occurring, in Latin America. A combination of risks converged that are not unique to countries and cities in the region and in fact are present in parts of India. These include: (1) rapid unregulated urbanisation, (2) extreme vertical and horizontal inequality, (3) exceedingly high rates of impunity, (4) the expansion of the illicit drugs trade and repressive counter-narcotics measures, and (5) the expansion of arms availability and liberalisation of arms access. There are of course other explanatory factors, but these consistently appear in the literature as primary factors.

Latin America is today the world's most urbanised region. The process of urbanisation has of course generated tremendous benefits - both in terms of real poverty reduction, improved wellbeing and economic growth. It has also generated tremendous downsides, not least a massive expansion in the urban poor, the growth of slums in and around cities, and new forms of social disorganisation and disorder. The speed at which the region urbanised bares consideration: in 1950 just 40 per cent of the population was urban, whereas today it is more than 80 per cent. By comparison, less than one-third of Indians live in cities, though this is changing rapidly, with vast proportions of the urban population forced to live in informal settlements. A failure to adequately manage the urban transition has knock-on effects, including the criminalisation of housing and service provision and the creation of no-go areas dominated by armed factions.

\section{The relationship between gun violence and poverty}

There is ample research that correlates social and economic inequality with higher rates of violence, including gun violence. When the poorest have few opportunities and the gaps between rich and poor grow, the economic benefits of crime tend to be greater. Inequality leads to more violent crime even in cities and municipalities with similar poverty levels. Latin America is one of the world's most unequal societies. After years of improvement, inequality is on the rise in Latin America. Research shows that inequality had declined in 16 of 17 countries in the region between 2000 and 2010, but these gains are stagnating. This has to do with lower growth in labour income at the bottom of the income pyramid, less effective social assistance and the diminished impacts of pension, among other things, In India, income inequality doubled between 1990 and 2010, and this has led India's richest 10 per cent to currently own 370 times the share of wealth that the poorest 10 per cent hold. 
Meanwhile, Latin American countries feature some of the highest rates of impunity in the world. Impunity for both criminal organisations, but also corrupt and abusive state institutions is a major constraint to development and citizen security. Honduras and Venezuela, for example, have impunity rates of more than 90 per cent. The fact is that the costs of committing gun-related violence are exceedingly low. The result is that gun-related violence is disproportionately high in most countries of Latin America. India, too, is contending with high rates of impunity, not least in relation to sexual violence. The 2015 Impunity Index places India in the worst 14 countries globally.

Latin America's dramatic increase in violence coincides with the expansion of drug production, trafficking, consumption and repression. It is a highly complex phenomenon, with national, regional and transnational dimensions. Three countries account for all of the world's supply of cocaine: Bolivia, Colombia and Peru. Violence, including gun-related violence, is associated with trafficking routes through Central America and most coastal regions. The business amounts to over US\$350bn a year with dramatic mark-ups in North America and Western Europe. Owing to counter-narcotic strategies funded in large part by the United States, established drug cartels are being fragmented, generating new forms of territorial organisation and trafficking routes, including via Africa and Asia.

Much less often discussed are military- and police-issue arms and ammunition leaked from existing Latin American government stockpiles. Weapons are also routinely pilfered from the current stocks of the armed forces and police. The leakage is considerable and probably one of the key sources of weaponry sustaining criminal organisations, drug trafficking gangs, private security firms, militia and others in the region. Arms transfer agreements are only weakly adhered to and applied.

\section{Implications for policies and programmes dealing with gun-related crime in Indian cities}

There is a veritable silence in Indian public debate on the problems of violence, including gun-related violence. There are periodic outbursts associated with high-profile incidents involving sexual violence, but the scale and magnitude of India's public security challenges are under-diagnosed. There is also a resounding silence from Indian diplomats and policymakers on the challenges posed by arms and armed violence to Indian society. India is conspicuously absent from the Arms Trade Treaty (ATT) and the Small Arms Programme of Action in the United Nations. The fact that India is a producer of arms and ammunition is perhaps partly to blame.

\section{High potential for connecting up with international policy frameworks}

Interventions at the national and city level in India can draw impetus by linking up with several key international agreements and treaties:

\section{Sustainable Development Goal (SDG) 16}

The first target of this goal calls for states to 'significantly reduce all forms of violence and related death rates everywhere'. The second target demands an end to 'abuse, exploitation, trafficking and all forms of violence against and torture of children'. SDG 16 proposes a number of pathways to achieving safer and more just societies. For example, it urges states to double down on the rule of law to ensure equal access to justice (target 3) as opposed to punitive policing and incarceration. It also makes the case to curb illicit financial flows, arms and corruption (targets 4-5) and invest in more effective, participatory and transparent government (targets 6-10).

\section{Sustainable Development Goal 11}

SDG 11 emphasises the critical role of adequate, safe and affordable housing as well as more predictable basic services. Likewise, it calls for redoubling investment in affordable (public) transportation, participatory planning in city decision-making, disaster risk planning, environmental protection, more attention to public spaces and resilient infrastructure. Many of these measures are known to have positive knock-on effects on wellbeing and living standards. The extent to which they contribute to the prevention of violence and improvements in safety is less well known.

\section{Arms Trade Treaty (ATT) and Programme of Action}

The ATT explicitly demands that states place upholding human rights laws and IHL (International Humanitarian Law) at the core of their arms export decisions. Signatories to the treaty are also required to prevent arms transfers that would abet terrorism, organised crime, gender-based violence or violence against children. India has established a National Coordination Agency under the Programme of Action to Prevent, Combat and Eradicate the Illicit Trade in Small Arms and Light Weapons, which focuses on establishing measures for states to manage all aspects of arms transfers, arms brokering, stockpile management, and marking and tracing. Nevertheless, India abstained from signing the ATT in 2014. 
More fundamentally, India frames the challenges of armed violence and arms availability as a 'terrorism' problem involving more emphasis on security measures and tightening border controls. The wider underlying structural factors and the importance of a 'preventive' approach are not prioritised. Nonetheless, there is some incipient research underway on better understanding the challenge, including from the Small Arms Survey. Likewise, groups such as the Institute for Peace and Conflict Studies, the Regional Centre for Strategic Studies and others have also undertaken very preliminary research, though this tends to be framed in a more hard regional and national security framework, and based on highly qualitative and anecdotal evidence.

\section{Recommendations}

1. The Government of India and civil society groups should revisit and engage more productively with global policy instruments, agreements and treaties on arms control. The regional arms control policy environment, while challenging, could be strengthened through a more evidence-based debate on the scale and magnitude of the challenges in India.

2. Re-orient policies and programmes pertaining to gun-related crime towards 'public health' and 'preventive' frameworks, rather than group all such initiatives under the banner of 'anti-terror' activities. Criminal violence generates at least ten times more deaths and injuries in India than terrorism and conflict.

3. The relationship between gun crime and urbanisation is complex, and efforts should not focus only on the largest cities: the most violent cities are not mega-cities, but mid-sized cities of between 1 and 3 million people. These mid-sized cities continue to grow rapidly, with severely under-resourced services and police forces, and with a growing population of unemployed youth.

4. There is an urgent need to invest in better systems for monitoring and analysing data of firearm and narcotics-related crime. Integrated systems are needed to link up city-, state- and national-level crime data, and with a view to provide real-time monitoring coupled with long-term trend analyses. This may involve more engagement with the United Nations Office on Drugs and Crime (UNODC), but also Interpol and other actors.

5. Storage and destruction policies governing out-dated or surplus state-owned firearms need an urgent overhaul, outlining clear strategies and objectives, and look to achieve greater levels of standardisation between national, state and city-level arsenals. These need to be complemented by the usage of embedded RF tags and tracers (including in gunpowder) for all state-owned firearms to aid detection of stolen/lost/hidden firearms.

6. Simplify procedures of firearms licensing and renewals for civilians. Current licencing regulations are complicated, involve multiple state agencies, and are largely ineffective.

\section{Further reading}

Parker, S. (2011) 'Balancing Acts: Regulation of Civilian Firearm Possession', in E. Berman et al. (eds), Small Arms Survey 2011: States of Security, Cambridge: Cambridge University Press

Small Arms Survey (2014) Small Arms of the Indian State: A Century of Procurement and Production, India Armed

Violence Assessment Issue Brief 4, Geneva: Small Arms Survey

\section{Credits}

This Rapid Response Briefing was written by Robert Muggah and Jaideep Gupte and reviewed by Robin Luckham. Further support and editing was provided by Sophie Robinson and Hannah Corbett. The opinions expressed are those of the authors and do not necessarily reflect the views of IDS.

Readers are encouraged to quote and reproduce material from issues of Rapid Response Briefings in their own publication. In return, IDS requests due

acknowledgement and quotes to be referenced as above.

The material has been funded by UK aid from the UK Government. However the views expressed do not necessarily reflect the UK Government's official policies.

(C) Institute of Development Studies, 2015

AG Level 2 Output ID: 273

\section{Institute of Development Studies}

IDS Rapid Response Briefings are published by the Institute of Development Studies and aim to provide high-level analysis of rapidly emerging and unexpected global events and their impact on development policy and practice. To subscribe: www.ids.ac.uk/idsrapidresponsebriefings

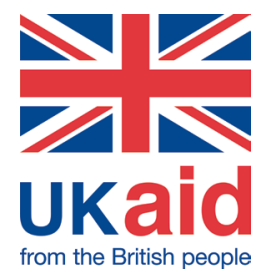

Institute of Development Studies, Brighton BN1 9RE UK

T +44 (0) $1273606261 \mathrm{~F}+44$ (0) 1273621202 E ids@ids.ac.uk W www.ids.ac.uk 